\title{
The genre repertoires of Norwegian beauty and lifestyle influencers on YouTube
}

\author{
Aleksander Torjesen \\ Department of Nordic and Media Studies, University of Agder, Norway
}

\begin{abstract}
YouTube represents an increasingly popular cultural phenomenon in the contemporary Norwegian media landscape. Since the inception of the digital video platform over 15 years ago, personal videoblogging has emerged as one of its dominant types of user-generated content. In this article, I draw from New Rhetoric genre theory and netnographic approaches to explore the beauty and lifestyle sphere on YouTube, in which several emergent genres are situated within a new media ecosystem. Through a qualitative content analysis of seven established Norwegian YouTube channels, a total of 17 individual genres were identified. Furthermore, I elaborate upon how informational, instructional, and confessional communicative functions are utilised in audiovisual publications through conventionalised digital media production practices.
\end{abstract}

Keywords: YouTube, social media, vlog, communicative functions, genre

\section{Introduction}

Entrepreneurially minded YouTubers in the contemporary beauty and lifestyle discourse sphere employ a diversity of complex genres throughout their channels, drawing on particular communicative functions in order to cater to already established audiences and to accumulate new subscribers. Several previous studies have made efforts to categorise the vast amount of digital video publications on YouTube, as well as the various cultural aspects in which they are embedded (Burgess \& Green, 2009; Gannon \& Prothero, 2018; García Rapp, 2017a, 2017b; Simonsen, 2011; Tolson, 2010). Although early videoblogging practices date back to crudely produced webcam confessionals popularised over a decade ago, there is still a lack of sufficiently detailed descriptions and typologies accounting for the numerous emergent genres that now span YouTube.

This article explores the genre repertoire and key communicative functions of publications found on established Norwegian YouTube-channels specialising in the production of beauty and lifestyle media. Individual publications on YouTube encompass several composite audiovisual elements, including videos, titles, descriptions, and thumbnail images, all uploaded and shared by registered users. By using a dataset of 386 native

Torjesen, A. (2021). The genre repertoires of Norwegian beauty and lifestyle influencers on YouTube. Nordicom Review, 42(2), 168-184. https://doi.org/10.2478/ nor-2021-0036 
YouTube publications uploaded on seven individual channels in 2019, I approach the YouTube videoblogging phenomenon in a Norwegian context based on the following research questions: What characterises the genres of the Norwegian beauty and lifestyle sphere on YouTube? Which central communicative functions do these genres rely upon, and how are they incorporated in the audiovisual publications? This study expands the literature on digital genres, media production practices, and user-generated content by mapping the genre repertoire of beauty and lifestyle channels in a contemporary Norwegian context. I provide detailed descriptions of key characteristics relating to settings, locations, and compositions, as well as specific communicative functions found in the genre repertoire.

\section{YouTube and videoblogs}

During the past 15 years, there has been an immense increase in both the distribution and the consumption of digital streaming media. Internationally, YouTube now boasts a billion hours of daily video consumption and a registered global userbase amounting to nearly one-third of Internet users (YouTube, n.d.). The website undoubtedly appeals to a diverse range of users and has played a significant role in the emergence of user-generated content (Burgess \& Green, 2009). In a Norwegian context, YouTube represents the most popular destination for digital video consumption amongst children and adolescents (Medietilsynet, 2020). Although the beauty and lifestyle phenomenon has been at the centre of substantial media coverage raising concerns about the effects influencer marketing may have on adolescents and children, research on the media they consume, its characteristics, and production practices remains fairly limited.

YouTube publications labelled as videoblogs (vlogs) span a diverse range of topics, themes, and styles. Yet many successful vlogs appear to share a number of common features: the publications are user-generated and are intrinsically tied to the practice of sharing (confessing) personal experiences and opinions in a serialised manner, presented on channel pages in reverse-chronological order. In their seminal work on YouTube, Burgess and Green (2009: 43) describe vlogs as "the conversational form that is somewhat emblematic of YouTube's user-created content". This is largely characterised by how the genre is tied to distinct communicative practices reminiscent of "interpersonal face-to-face communication" (Burgess \& Green, 2009: 54). In a more recent work about YouTube, Benson (2017: 120) defines vlogs as a "genre of YouTube video in which the creator directly addresses the viewer by speaking directly to the camera". However, this definition does not differentiate between the numerous genres and subgenres featuring communicative traits involving direct camera address. The lack of nuance means that the definition would also account for the variety of genres that have found a place on YouTube. Thus, not all videos on YouTube featuring a creator addressing the viewer by speaking directly into the camera can - or should - be referred to as vlogs.

Stylistically, what appears to separate the publications of YouTubers from other digital media is a "standardised YouTuber/vlog aesthetic, incorporating now familiar rapid-fire speech, jumpy and stylised editing, 'insider' jokes, community shout-outs and collaborations" (Cunningham \& Craig, 2017: 78). However, these descriptions are broad and general, and only account for inherent aesthetics, rather than how these aesthetics only represent a facet of a complex system of attributes which all contribute 
to fulfil specific communicative purposes. Additionally, contemporary research does not appear to account for how these aesthetics are produced as a result of specific production practices.

\section{Beauty and lifestyle channels}

Beauty and lifestyle channels have grown to be among the most populous and engaging spheres of user-generated content on YouTube, both in Norway (Medietilsynet, 2018) and internationally (Pixability, 2015, 2018). These channels represent a space where YouTubers can establish themselves as trustworthy sources of information and instructions within their respective fields of interest (Cunningham \& Craig, 2017; García Rapp, 2017b). Their subject matter generally revolves around cosmetics and fashion, whilst at the same time emphasising the YouTubers' "ordinary, everyday character" (Marôpo et al., 2020: 33) by chronicling their personal lives as digital autobiographies (García Rapp, 2017b).

García Rapp (2017a, 2017b) has conducted comprehensive research regarding beauty and lifestyle on YouTube. Her studies are largely focused on the British-Chinese YouTuber Bubzbeauty, whose video uploads, García Rapp (2017b) argues, can be placed in two categories: the "commercial sphere" (content-oriented tutorials and market-oriented reviews) and the "community sphere" (relational vlogs and motivational self-help guides). However, there is a lack of research addressing exactly how beauty and lifestyle YouTubers communicate, regarding how audiovisual publications are produced, and what genres they draw upon.

\section{Perspectives on genre}

Drawing from the New Rhetoric approach (Miller, 1984; Miller \& Shepherd, 2004), in this article I adopt a broad view on genre as "socially recognized types of communicative actions" (Orlikowski \& Yates, 2002: 14) and examine these based on their "socially recognized purpose and by their common characteristics of form" (Orlikowski \& Yates, 2002: 14-15). This involves exploring YouTube publications as texts produced through practices situated within a specific social context and describing instances in which genre knowledge is invoked to convey meaning based on the conventions and expectations of a discourse community, and ultimately to fulfil a communicative purpose (Lüders et al., 2010). Bhatia (1993: 46) argues that the "communicative purpose which the genre is intended to serve is the most important factor in genre identification". However, the purpose of new digital media genres is not always singular, but consists of complex and layered multiplicities of purposes being enacted simultaneously. These may include commercial, social, creative, entrepreneurial, and educational purposes, amongst others. Communicative functions represent the means used to fulfil communicative purposes and can be understood by examining how YouTubers "exploit available semiotic resources and modes of communication to achieve their professional goals" (Bhatia, 2015: 14). This suggests that the specific communicative functions utilised to fulfil one or more purposes constitute a crucial factor in understanding and identifying digital genres. 


\section{Data collection and methods}

My methodological approach draws from Bengtsson's framework for conducting qualitative content analysis (Bengtsson, 2016) and is inspired by explorative data immersion and extensive use of fieldnotes derived from netnography (Kozinets, 2010; Langer \& Beckmann, 2005). The analytical process consisted of four stages: 1) data identification and collection; 2) corpus demarcation and refinement; 3 ) coding based on inductive identification of recurring textual patterns and communicative functions; and 4) compilation and presentation of results.

Stage 1 identified YouTube channels that met the set selection criteria: candidates had to be at least 18 years of age, have a minimum of 10,000 subscribers, and feature publications in Norwegian containing beauty and lifestyle-related practices. The criteria were developed to ensure that the channels were well-established and had achieved a certain level of success whilst sharing a common sociocultural context. Eligible channels were identified by accessing several open online sources, including web searches, newspaper and magazine articles, the social media statistic provider Social Blade, and information provided by the leading multichannel influencer agencies in the Nordic region: Splay Norge, United Screens, and Nordic Screens. The owners of eligible YouTube channels were then approached and asked to participate in the study. Twenty-seven YouTubers who met the criteria were identified and approached using contact information on their YouTube channels, out of which seven gave their consent and allowed access to their YouTube channels. The project was approved by NSD (Norwegian Centre for Research Data), and all identifiable participants included in this article have consented to the use of screenshots and citations from their YouTube channels in publications.

Stage 2 involved utilising netnographic approaches, which encourages immersive data exploration and the production of systematic fieldnotes (Kozinets, 2010; Langer \& Beckmann, 2005). Large portions of YouTube publications were initially consumed to gain a sufficient understanding and familiarity with the data and its surrounding context. A contemporary time period was demarcated - between 1 Januray and 31 December 2019 - and a finalised corpus was established consisting of 386 individual videos published on seven YouTube channels, with audiences ranging between 10,200 and 117,000 subscribers.

Stage 3 consisted of analysing genres by identifying recurring terminology used by the YouTubers to label and categorise their publications and how these terms correlate with the contents of videos. Depictions of activities and production practices represent "series of textual features" (Larsen, 2002: 133) found across the different channels. Recurring genres and their communicative functions were categorised based on comprehensive fieldnotes derived from the initial netnographic data exploration. The analysis identified genres as "classes of communicative events which typically possess features of stability, name recognition and so on" (Swales, 1990: 9), through the observation of recurring elements constituting shared sets of content, form, and function. This includes 1) labels ascribed by the publishers themselves in auditive descriptions of videos, thumbnail images, superimposed title cards, video titles, and descriptions; and 2) by depictions of recurring enacted activities, narrative structures, and thematic commonalities which correlate with the ascribed labels. A subsequent inductive interpretation of the coded data then resulted in the identification of three prominent communicative functions: instructional, informational, and confessional. To investigate how these 
functions are employed, an analytical distinction was drawn between the auditive and visual aspects of the data, representing the two main modes of communication featured in the publications.

Through an inductive analysis of typified communicative actions and production practices, a total number of 17 individual recurrent categories (genres) were identified across the entirety of the dataset. This resulted in a compiled list of a connected system of genres (Bazerman, 1994) in which individual genres together represent the shared "genre repertoire" (Orlikowski \& Yates, 1994) of the YouTube channels (stage 4).

Due to the limited number of respondents, the findings from the analysis are not representative of the entirety of YouTubers fitting the selection criteria. Additionally, the data alone are unable to account for the motivations of YouTubers or the experiences of consumers. However, a mapping of genres and communicative functions provide insight into contemporary media production practices taking place within the domain of YouTube by increasingly professionalised media producers. I have translated the transcribed excerpts from Norwegian to English.

\section{Findings}

\section{Genre repertoire}

Table 1 shows an overview of the full genre repertoire, along with descriptions of the 17 individual genres' key features and characteristics. The videos were found to consist of three main types of footage, which describe certain traits relating to setting, location, and composition: sit-down footage; slice-of-life (SOL) footage; and behind-the-scenes (BTS) footage. Furthermore, these genres were found to be intrinsically reliant upon the three central communicative functions: instructional, informational, and confessional. Though overlapping, these functions are deployed at different times and emphasised for different purposes depending on the genre. They enable YouTubers to enact different roles and personae in order for their performances to complement the different themes and subject matter being featured.

Publications may either be focused entirely on a singular genre or contain several genres. For example, a publication titled "VLOG, DECLUTTER \& BIG UNBOXING! //SANNE SKAR” [VLOG, DECLUTTER \& STOR UNBOXING! //SANNE SKAR] contains the vlog, declutter, and unboxing genres as sequential segments, as reflected in the title (Sanne Skar, 2019c). Other publications, such as "BLACK FRIDAY | junkyard haul" (Isabel Hamre, 2019e), are entirely focused on the haul genre. Furthermore, numerous publications do not explicitly reference any genres in the title or thumbnail, yet depict activities which clearly correlate with the denotations of genre-specific terms used elsewhere. The genre-specific terms refer to specific depicted activities, footage types, and communicative functions which together represent discursive communicative actions that have acquired a "common name within a given context or community" (Miller \& Shepherd, 2004: 2). These were found to be recurring and used similarly across the seven channels. The vlog genre was the most salient, whilst the tour genre was published least frequently. Disparities regarding publication frequency, however, are vague, due to the convergent and overlapping character of the genres. 
The genre repertoires of Norwegian beauty and lifestyle influencers on YouTube

Table 1 Classification of genre repertoire

\begin{tabular}{|c|c|c|c|}
\hline Genre & Description & Footage & Function \\
\hline vlog & $\begin{array}{l}\text { YouTubers engaging in seemingly unscripted and sponta- } \\
\text { neous everyday life activities. Does not require a specific } \\
\text { situation, structure, or narrative. }\end{array}$ & SOL, BTS & confessional \\
\hline haul & $\begin{array}{l}\text { YouTubers describing and reviewing recently obtained } \\
\text { products. }\end{array}$ & sit-down & $\begin{array}{l}\text { informational, } \\
\text { confessional }\end{array}$ \\
\hline challenge & $\begin{array}{l}\text { YouTubers performing one or more tasks (challenges). Largely } \\
\text { tied to ephemeral trends on social media. }\end{array}$ & $\begin{array}{l}\text { sit-down, } \\
\text { SOL }\end{array}$ & confessional \\
\hline $\begin{array}{l}\text { Q\&A (question } \\
\& \text { answer) }\end{array}$ & YouTubers answering questions posed by audience members. & sit-down & confessional \\
\hline unboxing & $\begin{array}{l}\text { YouTubers opening boxes, reviewing their contents, and } \\
\text { sharing immediate thoughts. }\end{array}$ & sit-down & $\begin{array}{l}\text { informational, } \\
\text { confessional }\end{array}$ \\
\hline routine & $\begin{array}{l}\text { YouTubers enacting routine activities from their lives. Variants } \\
\text { include morning, evening, skincare, diet, and workout } \\
\text { routines. }\end{array}$ & SOL, BTS & $\begin{array}{l}\text { confessional, } \\
\text { informational, } \\
\text { instructional }\end{array}$ \\
\hline how-to / tutorial & $\begin{array}{l}\text { YouTubers sharing guides and tutorials on how to perform } \\
\text { one or more activities to achieve a particular result. }\end{array}$ & sit-down & $\begin{array}{l}\text { instructional, } \\
\text { confessional }\end{array}$ \\
\hline $\begin{array}{l}\text { best of / } \\
\text { favourites }\end{array}$ & $\begin{array}{l}\text { YouTubers discussing their experiences with products. } \\
\text { Variants include best of, favourite, least favourite, must haves, } \\
\text { recently bought, and most used. }\end{array}$ & sit-down & $\begin{array}{l}\text { informational, } \\
\text { confessional }\end{array}$ \\
\hline product test & $\begin{array}{l}\text { YouTubers testing products or services and subsequently } \\
\text { reviewing them, often based on their first impressions. }\end{array}$ & sit-down & $\begin{array}{l}\text { informational, } \\
\text { confessional }\end{array}$ \\
\hline story time & $\begin{array}{l}\text { YouTubers sharing humorous, embarrassing, or intimate } \\
\text { stories from their personal lives. }\end{array}$ & sit-down & confessional \\
\hline girl talk & $\begin{array}{l}\text { YouTubers answering questions and discussing topics } \\
\text { related to female puberty and coming of age. }\end{array}$ & sit-down & $\begin{array}{l}\text { confessional, } \\
\text { instructional }\end{array}$ \\
\hline declutter & $\begin{array}{l}\text { YouTubers tidying up and sorting various products. May } \\
\text { contain critique or descriptions of products. }\end{array}$ & BTS & $\begin{array}{l}\text { confessional, } \\
\text { informational }\end{array}$ \\
\hline pack with me & $\begin{array}{l}\text { YouTubers packing clothes and traveling supplies whilst } \\
\text { chatting about their personal lives and the commodities } \\
\text { shown on screen. }\end{array}$ & BTS & $\begin{array}{l}\text { informational, } \\
\text { confessional }\end{array}$ \\
\hline $\begin{array}{l}\text { GRWM (get } \\
\text { ready with me) }\end{array}$ & $\begin{array}{l}\text { YouTubers applying makeup and "getting ready" whilst con- } \\
\text { versing about their lives, cosmetics, and makeup application. }\end{array}$ & sit-down & $\begin{array}{l}\text { confessional, } \\
\text { instructional }\end{array}$ \\
\hline reaction & $\begin{array}{l}\text { YouTubers consuming media and sharing immediate } \\
\text { reactions. }\end{array}$ & sit-down & confessional \\
\hline mukbang & $\begin{array}{l}\text { YouTubers eating, often whilst reading and discussing com- } \\
\text { ments and direct messages. }\end{array}$ & $\begin{array}{l}\text { sit-down, } \\
\text { SOL }\end{array}$ & confessional \\
\hline tour & YouTubers presenting their personal or professional spaces. & BTS, SOL & confessional \\
\hline others & $\begin{array}{l}\text { Music videos, pranks, ASMR (autonomous sensory meridian } \\
\text { response), channel announcements, and maintenance. }\end{array}$ & $\mathrm{n} / \mathrm{a}$ & $\mathrm{n} / \mathrm{a}$ \\
\hline
\end{tabular}

The genre repertoire contains several general commonalities in terms of their production processes, resulting in a consistent overarching audiovisual style. The most notable visual aspects were found in recurrent characteristics relating to conventionalised uses of different settings, locations, and the compositional framing of shots.

\section{Setting, location, and composition}

A large majority of the publications were found to share several central common characteristics, in that they were recorded in a similar setting and edited using similar tech- 
niques involving the frequent use of jump-cuts, superimposed text, and added licencefree music. With regards to setting and location, three main approaches to recording footage were found: 1) sit-down videos, where YouTubers are communicating directly to a stationary camera set in interior recording-studio locations; 2) behind-the-scenes footage; and 3) slice-of-life footage shot seemingly spontaneously, often situated in exterior locations. These three approaches can be conceptualised as central types of formal characteristics, which are used in the configuration of genres.

The sit-down videos (approach 1) set in an interior home-studio location was found to be the most common setting across all the genres identified. These appear to be linked to genres constituted by depictions of recurring and repeatable activities and are highly stable and conventional in terms of production. Genres typically utilising sit-down settings include reaction, Q\&A, story time, girl talk, GRWM (get ready with me), haul, unboxing, showcasing, and how-to/tutorials. Other genres that may at times be recorded in such a setting include challenges, mukbang, and product tests. These do not require a fixed setting, but vary based on what the challenge consists of or what product is being reviewed. Sit-down videos are generally recorded at interior locations, often situated in personal living quarters with YouTubers placed centre-frame in close-up shots, where they function much like talking heads (see Figure 1).

Figure 1 Examples of locations and compositional practices found in sit-down footage

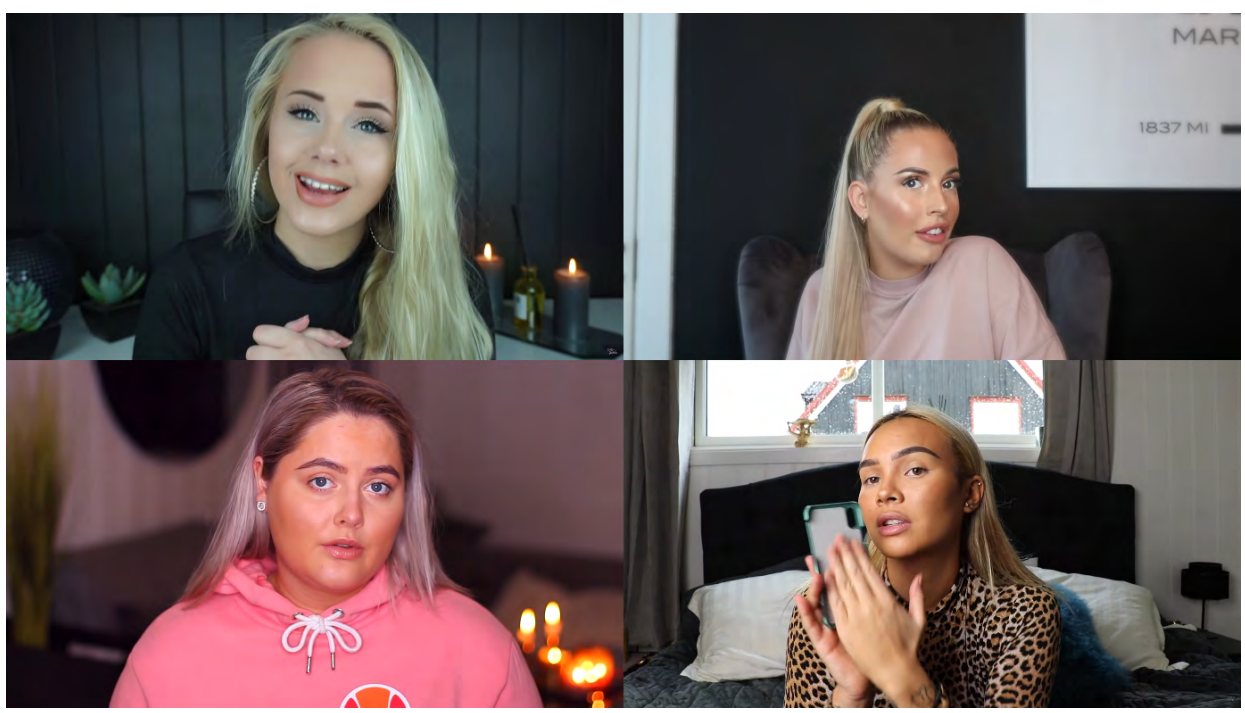

Source: Silje Jahren, 2019a; Isabelle Eriksen, 2019d; Sanne Skar, 2019b; Isabel Hamre, 2019c

Behind-the-scenes footage (approach 2) represents publications that deconstruct the façade surrounding the production process by allowing the audience to observe the surroundings of planned interior shots, such as the examples provided in Figure 1. BTS footage is prominent in the declutter, tour, routine, and pack with me genres. It is used frequently in declutter videos to shift the focus of the frame away from close-ups of the YouTuber by rotating the camera to reveal the otherwise out-of-frame vicinity of interior locations, thus emulating the YouTuber's own point of view. Figure 2 depicts how first-person perspective is used to emphasise abundances of commodities in the vlog and declutter genres. 
Figure 2 Behind-the-scenes shots used in the vlog and declutter genres

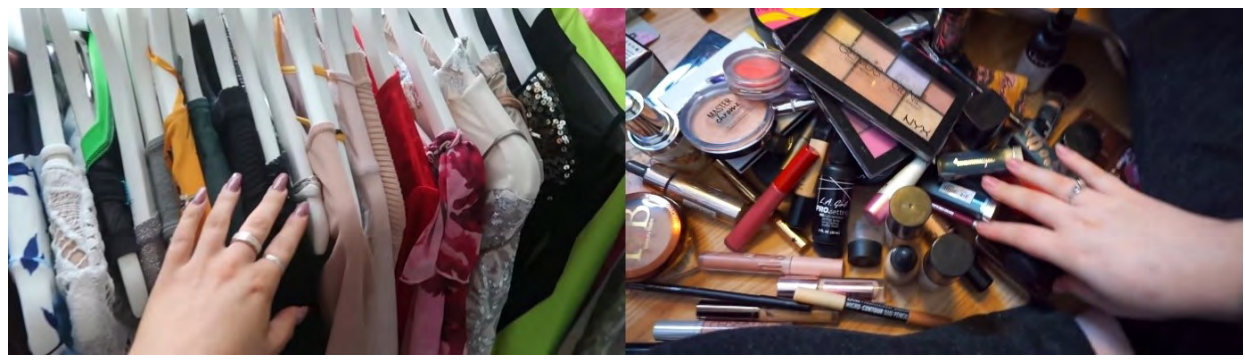

Source: Isabelle Eriksen, 2019c; Sanne Skar, 2019c

The third approach involves the recording of slice-of-life footage, where video production involves the use of a variety of seemingly unscripted and unplanned shots to chronicle events related to the YouTubers. The genre that appears to be least consistent when it comes to setting, production practices, and narrative is the vlog. Here, the premise is largely focused on either spontaneously documenting the experiences of YouTubers as they unfold, or staging reconstructions of daily activities. Whilst this genre may include footage utilising stationary and handheld cameras, it can also utilise either a third-person videographer, or feature the YouTuber directing the camera at themselves resulting in a "selfie" perspective (see Figure 3).

Figure 3 Slice-of-life footage recorded by a third person videographer and by using a selfie perspective

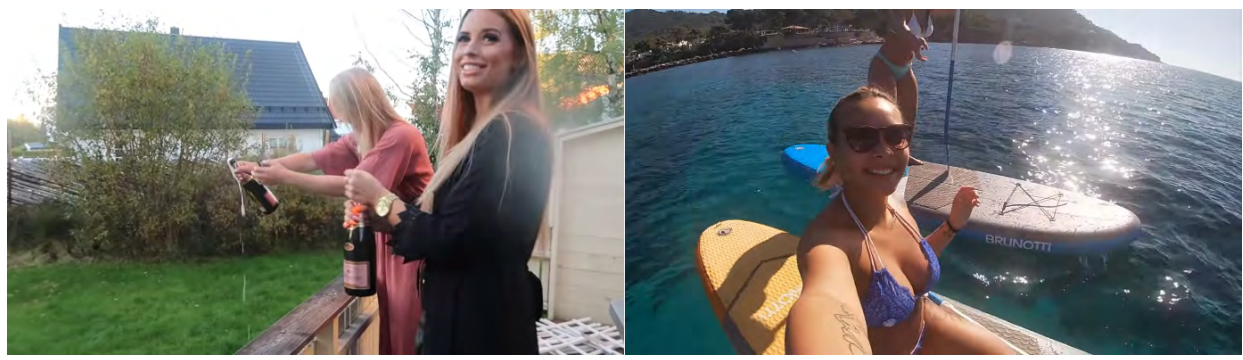

Source: Isabelle Eriksen, 2019e; Isabel Hamre, 2019a

\section{Communicative functions}

Across the 17 individual genres, three frequently utilised central functions were identified: confessional, informational, and instructional. These functions represent prevalent means of communication used to achieve specific purposes. They operate as both conventionalised norms used in the composition of specific genres and as resources which YouTubers can draw from in order to shape the aesthetic, style, and tone of the videos, and ultimately appeal to users through the enactment of different roles and personae.

By using a highly informal and conversational style of verbal speech and offering the viewer insight into their personal lives, the confessional function enables YouTubers to be perceived as the audience's personal friend, big sister, or role model. The informational function relates primarily to videos in which YouTubers take on the role of an expert, 
critic, or reviewer, whilst the instructional function is most prominent in tutorial-based genres featuring audiovisual demonstrations and guides that audiences can emulate.

\section{Confessional function}

The confessional function is prevalent across all the genres and relates to videos featuring personal expressions of emotions and experiences, and it is, arguably, one of the key elements of the distinctive style of videos associated with beauty and lifestyle channels. It is used to convey meaning related to the YouTuber's own personal life and is of particular importance in establishing producer-consumer relationships and engaging viewers through emotional investment. Without the confessional function, most videos would merely consist of objective descriptions or formal guides and instructions, with none of the personality and intimacy which have emerged as a paradigm of the beauty and lifestyle sphere on YouTube (Berryman \& Kavka, 2017; Burgess \& Green, 2009; Cunningham \& Craig, 2017; García Rapp, 2017a). Although the confessional function is utilised in all 17 genres identified in this study, it plays a prominent part in constituting the genres centred around practices involving documenting or recounting experiences from the YouTubers' own lives. These include the vlog, reaction, GRWM, routine, tour, Q\&A, challenge, mukbang, girl talk, story time, and pack with me genres.

Visual confessions represent video footage and written text in which images and writing are used in a self-exposing and revealing manner. This is frequently applied in genres incorporating BTS footage and footage that is otherwise set apart from a neutral or familiar studio location. It can be observed in how moving images can communicate specific details of YouTubers and their lifestyles through visual depictions of private spaces and personal activities. Visual confessions are also employed to achieve humorous, relatable, or authenticating effects by including unflattering images of themselves and their surroundings, thus "confessing" that despite their online celebrity status, they are seemingly ordinary and relatable. A video entitled "Pregnant? Trying to exercise \& Concert // VLOG” [Gravid? Prøver å trene \& Konsert // VLOGG] (Isabelle Eriksen, 2019a) is introduced with a montage lasting 1.38 minutes, featuring 11 different sequential shots depicting the YouTuber Isabelle Eriksen performing everyday activities, presumably representing her daily morning routine. The first three shots are stationary and consist of Eriksen waking up in her bed and putting on a bathrobe. The remainder of the montage proceeds by depicting her engaging in equally mundane activities, such as interacting with a computer, making breakfast, emptying the dishwasher, stirring a cup of coffee, applying makeup, and brushing her teeth (see Figure 4).

Despite its mundanity, this introductory sequence illustrates how the vlog genre can be utilised to visually communicate personal details. In this example, the YouTuber is confessing, through visual means, details that inform the viewer of what she wears after waking up, what she eats for breakfast, how she applies makeup, and so on. The sequence illustrates how YouTubers record footage of themselves enacting activities or reconstructing experiences from their own lives to communicate and manufacture a sense of intimacy by offering the audience perceived insight into their lifestyle.

Auditive manifestations of the confessional function represent publications in which the YouTuber reveals personal details through spoken words and vocalics. This is found throughout all the identified genres and is a vital facet in the complex constitution of 
Figure 4 Sequential shots from the opening montage of a vlog

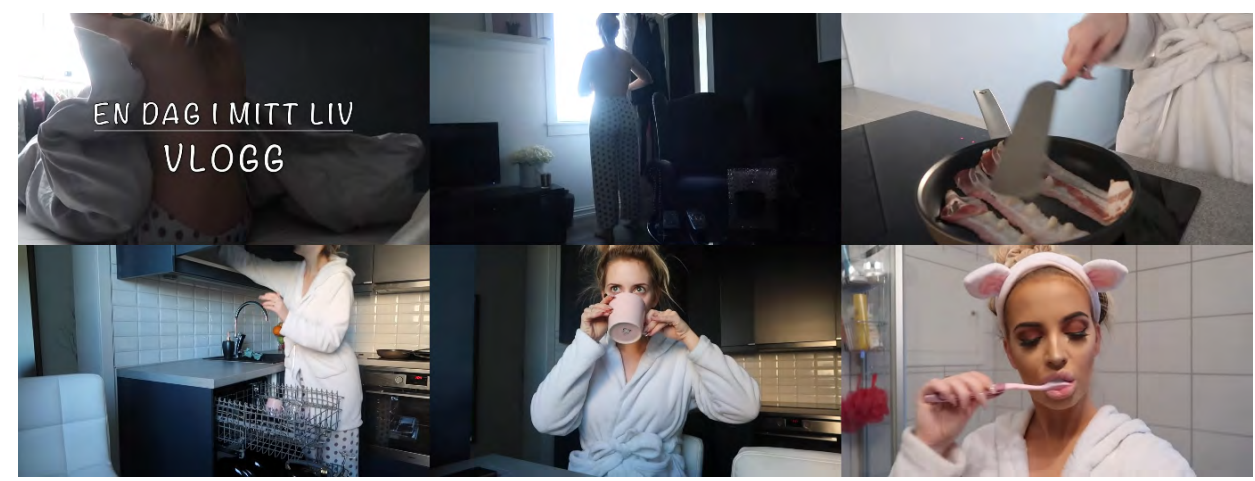

Source: Isabelle Eriksen, 2019a

the distinctively intimate tone. Auditive confessions are virtually indispensable in the reaction, story time, girl talk, Q\&A, and vlog genres, none of which are inherently tied to cosmetic or fashion products. The confessional function can be deployed auditively to imbue publications with a sense of humour, often in a revealing, self-deprecating manner. On the other hand, spoken confessions are also used by YouTubers to confide in their audience and share intimately personal details of a more serious matter. Following the sequence depicted in Figure 4, the video proceeds with a segment where Eriksen enters the bathroom whilst recording herself using a handheld selfie angle and confesses by speaking directly into the camera:

Okay. I must tell you something. I am so stupid [...] just now I took a pregnancy test because I am always terrified of becoming pregnant. Even if I have not had sex [...] I think I am pregnant all the time. And I am so scared of being pregnant [...] without knowing it. [...] So, I took a pregnancy test, and I am not pregnant.

That was all I wanted to say. (Isabelle Eriksen, 2019a)

The humorous tone of the otherwise serious monologue is implied by frequent interruptive non-verbal vocalic cues, including laughing, sneezing, and sighing, which are, presumably, deliberately included in the final publication. Despite making fun of herself and admitting to being "stupid", this illustrates how the YouTuber appears to confide in her audience. Narratively, this segment also functions as a payoff for the audience, in that it answers the question foreshadowed visually by the title of the publication, which indicates that the video will relate to pregnancy.

\section{Informational function}

The informational function draws upon the constructed ethos and reputation of the YouTuber as an expert authority in their respective field and allows them to engage in critiquing and reviewing practices. It is the prominent function in genres associated with the communication of detailed information regarding a specific theme, activity, product, or service. Review-oriented genres such as unboxing, first impressions, and product tests are particularly reliant upon sharing detailed and accurate product information, which very much depends on the informational function. 
Visually, the informational function is frequently used in genres featuring commodities, including haul, unboxing, first impressions, showcases, product tests, and to a lesser extent, tutorials and GRWM. These genres all largely rely upon depicting the various properties of products and services in a precise and detailed manner. YouTubers do so by exploiting the semiotic resources of the medium of digital video using extreme and medium close-up shots (see Figure 5).

Figure 5 Examples of visually conveyed product information in haul and unboxing videos

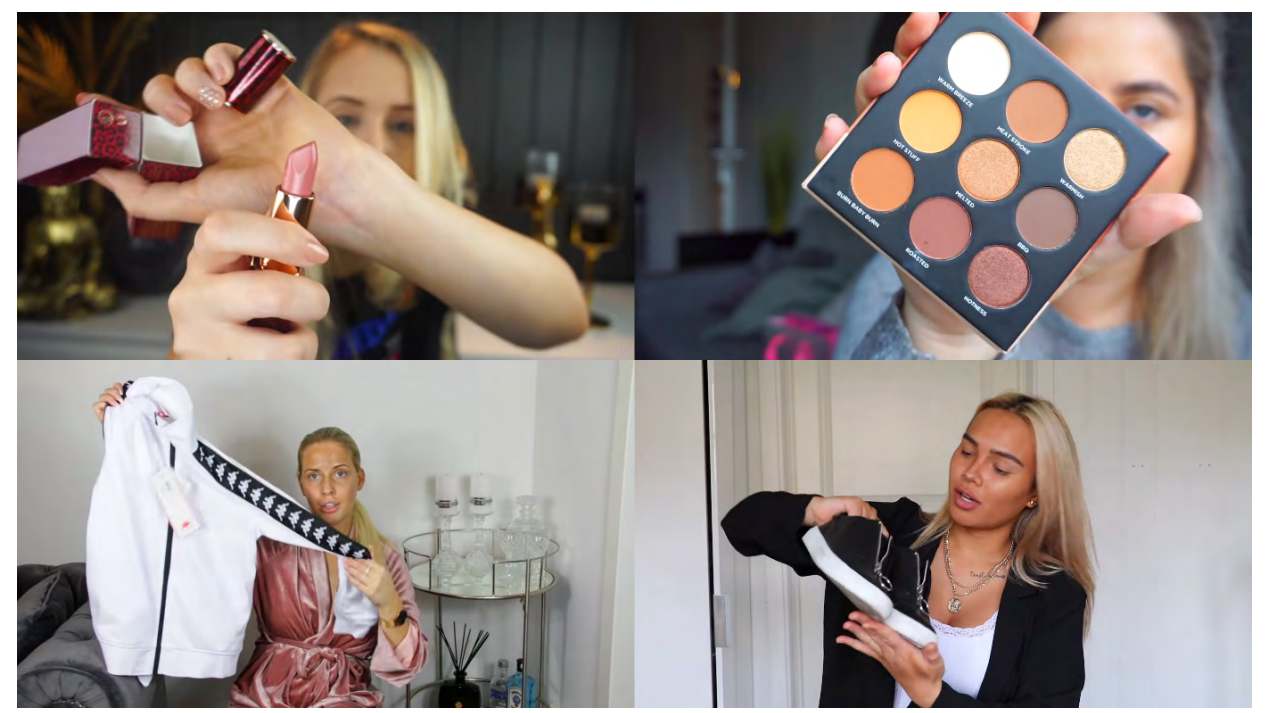

Source: Silje Jahren, 2019c; Sanne Skar, 2019c; Isabelle Eriksen, 2019b; Isabel Hamre, 2019b

By utilising the informational function in a visual manner, product review genres are effectively able to serve their purpose of informing viewers about the visual aspects of products. The medium of video allows for this information to be communicated in detail, particularly if the visual product information is consumed in concordance with written text found in the video description. These written descriptions may contain additional information, including where the depicted commodities can be obtained, their brand, sizing conventions, prices, and potential offers. Information such as this is often also provided through auditive means.

The informational function is used auditively to disseminate knowledge and information tied to specific subjects, topics, or items depicted in publications. It is frequently employed in genres featuring large amounts of products and services, including the unboxing, haul, declutter, showcase, tutorial, and routine genres. In these genres, the function is used by YouTubers to review and critique products and services by offering the audience spoken information in an ostensible and nuanced manner, whilst also constructing and reinforcing their role as industry experts and "beauty gurus".

In a showcasing product review genre video titled "2018 MAKEUP FAVOURITES // SANNE SKAR” [2018 SMINKE FAVORITTER! // SANNE SKAR] (Sanne Skar, 2019a) the YouTuber enacts the role of an expert, offering the audience information regarding products which she has obtained and used during the past year. Whilst reviewing a particular product, she explains how it is unobtainable for most of her audience: "I bought 
this at Walmart in the USA. [...] A lot of makeup artists are using this. [...] Buy it if you ever come across it when you are in the USA" (Sanne Skar, 2019a). By aligning herself with makeup artists and imbuing the product with a sense of exclusivity, she positions herself as an expert in the field of cosmetics. Much akin to the practices relating to the role of an expert critic in traditional media, her expertise and extensive interest in a specific subject grant her a position where her opinions on the matter are considered valuable. Due to the central focus on including detailed descriptions of commodities and their various properties, this "expert" role conflicts with the ordinariness and amateurish "everyday person" persona commonly associated with the phenomenon.

\section{Instructional function}

The instructional function represents a key element in publications where YouTubers enact the role of a teacher, tutor, guide, or consultant, and has a prevalent position in the tutorial, how-to, and GRWM genres. It enables YouTubers to take advantage of their perceived "expert" persona constructed by the informational function by engaging in practices where they demonstrate and portray specific skills and techniques, thus further reinforcing the expert persona through audiovisual depictions of them exhibiting their skills.

The instructional function enables publications to depict YouTubers demonstrating step-by-step instructions or guides in great detail. The how-to and tutorial genres are optimised to function instructionally in a visual sense based on exploiting technologically situated affordances. The combination of extensive lighting and high-definition video allows the footage to effectively communicate how the application techniques are performed (see Figure 6). Additionally, the embedded YouTube video player enables interactants to pause, rewind, or fast-forward, and thus to utilise the visual instructive footage in a non-linear fashion.

\section{Figure 6 Visually mediated step-by-step instructions}

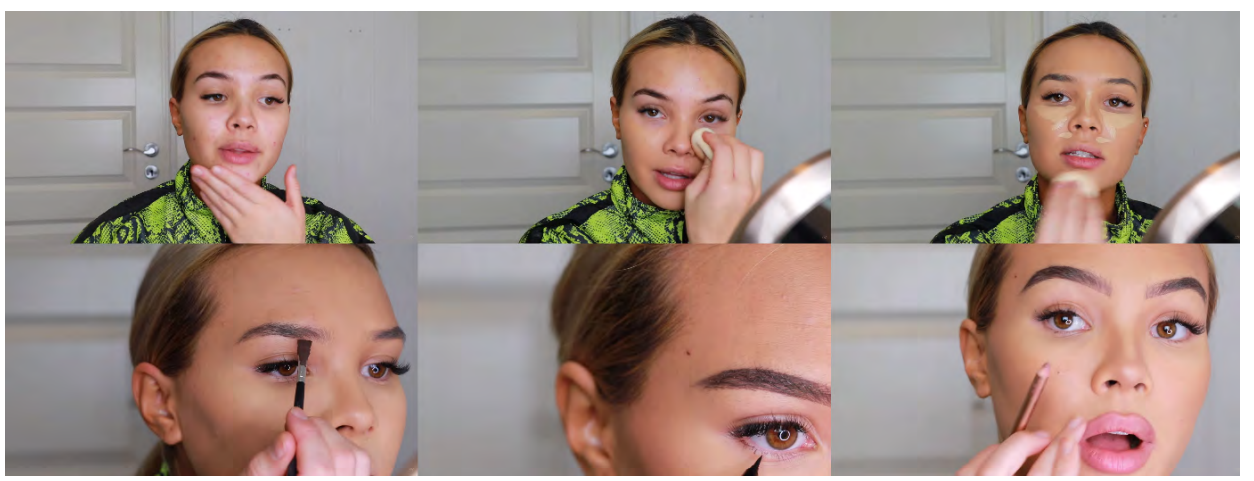

Source: Isabel Hamre, 2019d

Figure 6 depicts a tutorial segment from a makeup tutorial video, in which the YouTuber demonstrates how to achieve a look that she refers to as "my everyday makeup" through a sequential process of applying numerous cosmetic products. The footage draws on the instructional function by portraying 16 individual steps of makeup application, presented 
sequentially using a combination of close-ups and extreme close-up shots depending on the technique and area of application.

In addition to being an indispensable part of the tutorial genre, the instructional function was also found to be occasionally invoked orally throughout other types of sit-down videos. In the Q\&A publication entitled "SOLVING YOUR PROBLEMS (depression, cheating and relationships)" [LØSER DERES PROBLEMER (Depresjon, utroskap og forhold)] (Silje Jahren, 2019b), the YouTuber addresses issues and questions sent by her audience and offers instructive advice on topics including infidelity, house plants, mourning deceased relatives, mental health, and domestic relationships. After reciting a question asking for advice concerning mental health, the YouTuber responds in an advisory, yet instructional manner:

Unless you are doing something that takes you towards something you want to do, then I would quit doing it. [...] You are you, and you must live for your own sake.

And you must get rid of the people who do not accept that. (Silje Jahren, 2019b)

Here, the YouTuber is not only offering instructions, but also motivation and advice to her viewers. The YouTuber frequently invokes the confessional function to substantiate personal ethos and give credence to her instructional advice by confessing her personal experiences with the subject matter: "Believe me, I tried everything. I read self-help books, went to a psychiatrist. [...] I am not one hundred per cent well yet. [...] I know exactly what it is like to be depressed" (Silje Jahren, 2019b) This serves as an example of not only how YouTubers confide in their audience but also how the audience might confide in YouTubers. The emotional weight and trustworthiness of the advice afforded by the genres' instructional function is, in the context of this sequence, very much reliant upon the confessional function and self-disclosure to fulfil the purpose of "solving" the audience's problems. This illustrates how these functions can coincide and operate symbiotically, as the therapeutic consultant role enacted by the YouTuber quickly shifts to embody a more supportive and personal relationship.

\section{Discussion}

Based on a New Rhetoric perspective on genre theory (Bazerman, 1994; Miller, 1984; Miller \& Shepherd, 2004), the findings from this analysis expand on existing literature by offering detailed descriptions of how contemporary genres are complex configurations of specific formal traits relating to audiovisual production practices and depictions of specific activities. Furthermore, it illustrates that a crucial unifying characteristic of the genre repertoire can be observed in how the confessional function is employed to emphasise a sense of personable intimacy.

Beauty YouTubers have previously been described as a community of practice with "shared repertoires of language, tools and artefacts" (Gannon \& Prothero, 2018: 612). This study illustrates that they also share a genre repertoire, in which the production practices they engage in - and the ways in which they make use of the available language, tools, and artefacts - has resulted in a shared set of recurring genres. These genres are distributed and presented using a distinct set of genre-specific labels (see Table 1), which categorises the publications and informs the audience about what to expect in terms of their content, style, and form. In the "volatile environment of rapidly changing 
trends" (García Rapp, 2017b: 241) - that is, YouTube - the 17 genres identified in this study represent fairly stable forms of media publications within the social context of the beauty and lifestyle sphere.

Whereas some genres may appear more thematically linked to the beauty and lifestyle sphere than others, such as GRWM, which combines genre traits found in tutorials (depicting makeup application), Q\&A (informal conversation), and the vlog ("getting ready" for something which relates to the YouTuber's personal life), most genres appear to be far more versatile. The haul and unboxing genres, for instance, are by no means bound to cosmetic and fashion products. Neither are tutorials, which may offer instructions on anything from car repair to graphic design. However, the subject matter, which in this case is beauty and lifestyle, necessitates certain production practices related to setting, location, and composition.

Despite only making up a small portion of the Norwegian beauty and lifestyle community, there is nothing to suggest that the YouTube channels in this study differ significantly from other contemporary Norwegian beauty and lifestyle channels in terms of genres, functions, and production practices. Furthermore, the seven YouTubers largely resemble descriptions of beauty and lifestyle YouTubers in American (Cunningham \& Craig, 2017), Irish (Gannon \& Prothero, 2018), Canadian (Raun, 2018), British-Chinese (García Rapp, 2017a, 2017b), Portuguese and Brazilian (Marôpo et al., 2020), and English (Berryman \& Kavka; 2017; Tolson, 2010) contexts. The findings also correlate with existing research that has characterised beauty and lifestyle publications as intimate, informal, and seemingly authentic (Berryman \& Kavka; 2017; García Rapp, 2017a, 2017b; Marôpo et al., 2020; Raun, 2018) and details how YouTubers construct these characteristics using the means available to them.

The results from the analysis demonstrate how strategically planned video productions may be construed as sincere and spontaneously motivated based on their "performed authenticity" (Marôpo et al., 2020: 34), by recording reconstructions of everyday activities, such as waking up in one's bed (see Figure 5). Additionally, both behind-the-scenes and slice-of-life footage appear to be linked to staged performances of authenticity. YouTubers frequently "invite" their audience into their own personal spaces in genres such as declutter, pack with me, and tour. Furthermore, the everydayness of the vlog genre further emphasises the intimate connection YouTubers appear to share with their audience by deliberately portraying themselves in an unflattering manner. These types of footage represent a vital aspect relating to the form, content, and function of the genres. Portrayals of seemingly authentic activities and personal intimacy may therefore legitimise audience interest in personal opinions as it relates to the product reviews and tutorials. This, along with more explicitly mediated auditive confessions thus represent a motivating factor in generating engagement and traffic to instructional or informational genres, which may not have otherwise been of interest to said audience.

The various uses of the confessional function appear to be what epitomises the vernacularity and intimate informality associated with the beauty and lifestyle YouTuber phenomenon (García Rapp, 2017a; Raun, 2018; Marôpo et al., 2020; Berryman \& Kavka, 2017). Whereas early beauty channels have been described as largely containing instructive tutorials (Tolson, 2010), the results from this study suggest that the phenomenon has evolved to incorporate a more personable tone, where eccentricity, personality, and lifestyles are emphasised. 
Marôpo and colleagues (2020: 33) draw attention to the importance of frequently updating the audience regarding "whom and where the vloggers are, what they are doing and what their personal tastes and styles are". As the findings of this study demonstrate, this can be achieved through the employment of the confessional function, not just through auditive monologues and embodied performances, but also through visual depictions of everyday life. Whilst the concept of communicative functions does not directly conflict with the idea of commercial (tutorials and reviews) and community (vlogs and self-help guides) spheres (García Rapp, 2017b), the sphere-based categorisation does not account for how genres are often interconnected and can operate in several spheres at the same time. The haul genre, for instance, may be highly market oriented, but this study reveals it is also largely centred around sharing personal details, which combines the informational and the confessional function. This demonstrates that "market-oriented" reviews may also contain vital elements of "relational" personal disclosure.

The employment of the instructional function affords the investigated YouTubers the ability to enact specific roles depending on the situation and thematic context of the publications. Previous studies have pointed out that YouTubers position themselves as experts, teachers, and guides (García Rapp, 2017a; Tolson, 2010), without accounting for the audiovisual production practices that enables them to be perceived as such. The findings from this study elaborate upon these notions, and present exemplifications of how detailed close-up shots combined with auditive instructions are used to mediate step-by-step guides (see Figure 6) in which expertise and know-how is exhibited. Additionally, the informational function is frequently deployed to inform the audience about the properties of specific products. This is realised by simultaneously recording footage of close-up shots and auditive descriptions to convey visual details coupled with the YouTubers' own perceptions of depicted commodities (see Figure 5), thus utilising the affordances and potentiality of the digital video medium.

\section{Conclusion}

Beauty and lifestyle on YouTube represent an inherently personal form of communication in which audience members take part in imagined communities centred around an overarching narrative chronicling personal aspects of the portrayed YouTuber (García Rapp, 2017b). This article provides a descriptive mapping of the contemporary genre repertoire found on established YouTube channels within the Norwegian beauty and lifestyle sphere and elaborates upon central recurrent characteristics and common traits relating to the form, content, and function of genres. Drawing from a New Rhetoric perspective on genre combined with extensive netnographic fieldwork, the qualitative content analysis identified 17 individual genres and three key communicative functions.

Despite variations in terms of subject matter and narratives, most publications were found to be relatively stable in terms of composition and form. This is illustrated by how YouTubers primarily engage in three types of production practices relating to particular settings, locations, and compositional forms that are used in the footage. Furthermore, the study shows that the publications are indispensably bound to instructional, informational, and confessional functions, and how this is mediated through auditive and visual means of communication. The results of this study expand existing literature by detailing 
a repertoire comprised of emergent contemporary genres and providing descriptions of the specific terminology used to describe them and their various features.

\section{References}

Bazerman, C. (1994). Systems of genres and the enactment of social intentions. In A. Freedman, \& P. Medway (Eds.), Genre and the new rhetoric (pp. 79-101). Taylor \& Francis. https://doi. org/10.4324/9780203393277

Bengtsson, M. (2016). How to plan and perform a qualitative study using content analysis. NursingPlus Open, 2. https://doi.org/10.1016/j.npls.2016.01.001

Benson, P. (2017). The discourse of YouTube: Multimodal text in a global context. Routledge. https://doi. org/10.4324/9781315646473

Berryman, R., \& Kavka, M. (2017). 'I guess a lot of people see me as a big sister or a friend': The role of intimacy in the celebrification of beauty vloggers. Journal of Gender Studies, 26(3), 307-320. https:// doi.org/10.1080/09589236.2017.1288611

Bhatia, V. K. (1993). Analysing genre: Language use in professional settings. Longman.

Bhatia, V. K. (2015). Critical genre analysis: Theoretical preliminaries. HERMES - Journal of Language and Communication in Business, 27(54), 9-20. https://doi.org/10.7146/hjlcb.v27i54.22944

Burgess, J., \& Green, J. (2009). YouTube: Online video and participatory culture. Polity Press.

Cunningham, S., \& Craig, D. (2017). Being 'really real' on YouTube: Authenticity, community and brand culture in social media entertainment. Media International Australia, 164(1), 71-81. https://doi. org/10.1177/1329878X17709098

Gannon, V., \& Prothero, A. (2018). Beauty bloggers and YouTubers as a community of practice. Journal of Marketing Management, 34(7-8), 592-619. https://doi.org/10.1080/0267257X.2018.1482941

García Rapp, F. (2017a). "Come join and let's BOND”: Authenticity and legitimacy building on YouTube's beauty community. Journal of Media Practice, 18(2-3), 120-137. https://doi.org/10.1080/14682753.2 017.1374693

García Rapp, F. (2017b). Popularity markers on YouTube's attention economy: the case of Bubzbeauty. Celebrity Studies, 8(2), 228-245. https://doi.org/10.1080/19392397.2016.1242430

Isabelle Eriksen. (2019a, March 25). Gravid? Prøver å trene \& konsert // VLOGG [Pregnant? Trying to exercise \& concert // VLOG] [Video]. YouTube. https://youtu.be/Cdj8PQipIcU

Isabelle Eriksen. (2019b, April 24). Shoppet for 10000 kroner - TRY ON HAUL [Shopped for 10,000 kroner - TRY ON HAUL] [Video]. YouTube. https://youtu.be/McZr3nWGAbw

Isabelle Eriksen. (2019c, May 20). 17. MAI VLOGG - Party og moro (A) [17 MAY VLOG - Party and fun (A)] [Video]. YouTube. https://youtu.be/hGbw7Rg_4bc

Isabelle Eriksen. (2019d, July 23). Reagerer til FAN EDITS \& MEMES [Reacting to FAN EDITS \& MEMES] [Video]. YouTube. https://youtu.be/W1cji6L1v7c

Isabelle Eriksen. (2019e, October 1). OVERRASKER en FAN + TURN KONKURRANSE mot Erik [SURPRISING a FAN + GYMNASTICS COMPETITION versus Erik] [Video]. YouTube. https://youtu.be/OGWkXWud1ao

Isabel Hamre. (2019a, July 25). STAND UP PADDLE! | Mallorca vlogg dag 4+5 [STAND UP PADDLE! | Mallorca vlog day 4+5] [Video]. YouTube. https://youtu.be/YwSka5UxO7E

Isabel Hamre. (2019b, September 22). NELLY Haul og Try-On [NELLY Haul and Try-on] [Video]. YouTube. https://youtu.be/8UeZd8voAE0

Isabel Hamre. (2019c, October 1). JEG SKAL FLYTTE (igjen) !! [I AM MOVING (again) !!] [Video]. YouTube. https://youtu.be/GIxIyq4khmo

Isabel Hamre. (2019d, November 13). ETTERLENGTET SMINKEVIDE [LONG-AWAITED MAKEUP VIDEO] [Video]. YouTube. https://youtu.be/1Ce4da29bH8

Isabel Hamre. (2019e, November 25). BLACK FRIDAY | junkyard haul [Video]. YouTube. https://youtu.be/ DJysPchQRFU

Kozinets, R. (2010). Netnography: Doing ethnographic research online (2nd ed.). Sage.

Langer, R., \& Beckmann, S. (2005). Sensitive research topics: Netnography revisited. Qualitative Market Research, 8(2), 189-203. https://doi.org/10.1108/13522750510592454

Larsen, P. (2002). Mediated fiction. In K. Bruhn Jensen (Ed.), A handbook of media and communication research: Qualitative and quantitative methodologies (pp. 117-137). Routledge. https://doi. org/10.4324/9780203465103

Lüders, M., Prøitz, L., \& Rasmussen, T. (2010). Emerging personal media genres. New Media \& Society, 12(6), 947-963. https://doi.org/10.1177/1461444809352203

Marôpo, L., Jorge, A., \& Tomaz, R. (2020). "I felt like I was really talking to you!”: Intimacy and trust among teen vloggers and followers in Portugal and Brazil. Journal of Children and Media, 14(1), 22-37. https:// doi.org/10.1080/17482798.2019.1699589 
Medietilsynet. (2018). Barn og medier-undersøkelsen 2018: 9-18-åringer om medievaner og opplevelser [Children and media survey 2018: 9-18-year-olds about media habits and experiences]. https://medietilsynet. no/globalassets/publikasjoner/barn-og-medier-undersokelser/2018-barn-og-medier

Medietilsynet. (2020). Barn og medier 2020: En kartlegging av 9-18-åringers digitale medievaner [Children and media survey 2020: a mapping of 9-18-year-olds digital media habits]. https://www.medietilsynet.no/globalassets/publikasjoner/barn-og-medier-undersokelser/2020/201015-barn-og-medier-2020-hovedrapport-med-engelsk-summary.pdf

Miller, C. R. (1984). Genre as social action. Quarterly Journal of Speech, 70(2), 151-167. https://doi. org/10.1080/00335638409383686

Miller, C. R., \& Shepherd, D. (2004). Blogging as social action: A genre analysis of the weblog. Into the blogosphere, rhetoric, community and culture of weblogs. http://blogs.ubc.ca/ewayne/files/2010/03/AGenre-Analysis-of-the-Weblog.pdf

Orlikowski, W., \& Yates, J. (1994). Genre repertoire: The structuring of communicative practices in organizations. Administrative Science Quarterly, 39(4), 541-574. https://doi.org/10.2307/2393771

Orlikowski, W., \& Yates, J. (2002). Genre systems: Structuring interaction through communicative norms. The Journal of Business Communication, 39(1), 13-35. https://doi.org/10.1177/002194360203900102

Pixability. (2015). Beauty on YouTube: The social video beauty video ecosystem 2015. https://www.pixability. com/insights-reports/beauty-youtube-2015/

Pixability. (2018). The digital beauty counter: How beauty marketers can connect with consumers through YouTube, Facebook, and Instagram Video. https://www.pixability.com/insights-reports/digital-beauty-counter/

Raun, T. (2018). Capitalizing intimacy: New subcultural forms of micro-celebrity strategies and affective labour on YouTube. Convergence, 24(1), 99-113. https://doi.org/10.1177/1354856517736983

Sanne Skar. (2019a, January 7). 2018 SMINKE FAVORITTER! // SANNE SKAR [2018 MAKEUP FAVOURITES! // SANNE SKAR] [Video]. YouTube. https://youtu.be/DMwjFNJtMVo

Sanne Skar. (2019b, January 17). SVARER PÅ SPØRSMÅLET ALLE HAR LURT PÅ - Q\&A! [ANSWERING THE QUESTION EVERYONE HAS BEEN WONDERING ABOUT - Q\&A!] [Video]. YouTube. https://youtu.be/BoxWC-HVkjg

Sanne Skar. (2019c, February 25). VLOG, DECLUTTER \& STOR UNBOXING! - //SANNE SKAR [VLOG, DECLUTTER \& BIG UNBOXING! - //SANNE SKAR] [Video]. YouTube. https://youtu.be/ TD7AKX8e2jg

Silje Jahren. (2019a, January 31). SJUKE FUNFACTS DEL 2 / Viagra kan brukes til HVA? [SICK FUNFACTS PART 2 / Viagra can be used for what?]. [Video]. YouTube. https://youtu.be/LRYWNvp8N0I

Silje Jahren. (2019b, February 7). LØSER DERES PROBLEMER (Depresjon, utroskap og forhold) [SOLVING YOUR PROBLEMS (depression, cheating and relationships)] [Video]. YouTube. https://youtu.be/ CL8rBGyVDKU

Silje Jahren. (2019c, November 7). INNKJØP FRA SPANIA (brukte alt for mye penger) [PURCHASES FROM SPAIN (spent way too much money)] [Video]. YouTube. https://youtu.be/7FR8eyQKRZo

Simonsen, T. M. (2011). Categorising YouTube. Mediekultur: Journal of Media and Communications Research, 27(51), 72-93. https://doi.org/10.7146/mediekultur.v27i51.5483

Swales, J. (1990). Genre analysis: English in academic and research settings. Cambridge University Press.

Tolson, A. (2010). A new authenticity? Communicative practices on YouTube. Critical Discourse Studies, 7(4), 277-289. https://doi.org/10.1080/17405904.2010.511834

YouTube. (n.d.). Press. Retrieved October 19, 2020, from https://www.youtube.com/about/press/

(C) 2021 Nordicom and respective authors. This is an Open Access work licensed under the terms of the Creative Commons Attribution-NonCommercial-NoDerivatives 4.0 International Public licence (CC BY-NC-ND 4.0). To view a copy of the licence, visit https://creativecommons.org/ licenses/by-nc-nd/4.0/ 